\title{
Gene and protein expression profiles in the foetal liver of the pregnant rat fed a low protein diet
}

\author{
Christopher J. McNeil · Susan M. Hay • \\ Garry J. Rucklidge · Martin D. Reid · \\ Gary J. Duncan · William David Rees
}

Received: 7 May 2009/Accepted: 13 May 2009/Published online: 30 May 2009

(C) Springer-Verlag 2009

\begin{abstract}
Foetal growth is particularly sensitive to the protein content of the mother's diet. Microarray data from the foetal liver of pregnant rats fed normal (HP) or reduced protein diets (LP) were compared by gene set enrichment analysis. Soluble proteins from a second portion of the liver were analysed by two-dimensional gel electrophoresis. Genes associated with progesterone, insulin-like growth factor-1 and vascular endothelial growth factor were upregulated in HP compared to LP, in addition to genes associated with cell differentiation and signalling from the extracellular matrix. In contrast, cytokine signalling was downregulated. Proteomics showed that proteins associated with amino acid metabolism, mitochondrial function and cell motility were differentially abundant in the HP compared to the LP groups. These growth factor and extracellular matrix signalling pathways linked to cell motility may be important mediators of the changes in liver structure that occur in utero and persist into adult life.
\end{abstract}

Keywords Programming - Hepatic development .

Metabolism - Foetal origins of disease

\section{Introduction}

Animal studies have shown that foetal growth is particularly sensitive to the nutritional status of the mother [18]. For example, a modest reduction in the protein content of

C. J. McNeil · S. M. Hay · G. J. Rucklidge

M. D. Reid · G. J. Duncan · W. D. Rees ( $\square)$

Rowett Institute of Nutrition and Health, The University of

Aberdeen, Greenburn Road, Bucksburn, Aberdeen AB21 9SB,

Scotland, UK

e-mail:wdr@rri.sari.ac.uk the diet fed to the pregnant rat restricts the growth of the fetuses, producing irreversible changes in the ultrastructure of foetal organs including the liver $[2,15]$. Systems biology approaches including transcriptomics and proteomics offer a unique opportunity to study the complex mechanisms regulating the interaction between maternal nutrition and organ growth in the foetus.

The liver is one of the most complex organs in the body, carrying out over 5,000 functions, including an important role in the regulation of protein and carbohydrate metabolism. Changes in hepatic growth during foetal stages may underlie the associations between poor development in utero and the increased risk of metabolic disease in adult life [5]. We have investigated the effects of a modest reduction in the protein content of the maternal diet on the relative abundance mRNAs (the transcriptome) and of soluble proteins (the proteome) of the foetal liver using the laboratory rat as an animal model.

\section{Methods}

All experimental procedures were approved by the ethical review committee of the Rowett Research Institute and conducted in accordance with the UK Animals (Scientific Procedures) Act 1986. Four groups of 12 female Rowett Hooded Lister Rats were randomly assigned to one of four experimental diets from approximately 8 weeks of age. The composition of the diets containing $18 \%$ (w/w) (HP group) or $9 \%(\mathrm{w} / \mathrm{w})$ casein (LP group) and prepared with either corn or soya oil $(7 \%, \mathrm{w} / \mathrm{w})$ has been described previously [12]. After feeding the diets for approximately 2 weeks, the animals (body weight 200-250 g) were mated with normal males. On gestation day 21, dams were anesthetized, killed by cardiac puncture and rapidly 
dissected. After the fetuses were killed, tissues were rapidly removed, frozen in liquid nitrogen and stored at $-80^{\circ} \mathrm{C}$ until required. Analyses of foetal liver were carried out on tissues from six female pups, one chosen randomly from each litter. Females were used as these were shown to be more affected in adult life [11].

\section{Microarray analysis of gene expression}

A portion of the foetal liver was used for the preparation of total RNA using Trizol reagent (Sigma, Poole, Dorset, UK) and treated with DNAse as described previously [11]. All mRNA samples used had an RNA integrity number $>8$ (Agilent Bioanalyser) and sexing was verified by PCR [11]. Samples of RNA were hybridised to Affymetrix Rat Genome 2302.0 microarrays (Affymetrix, Santa Clara, CA, USA, provided through the NuGO array pipeline) by ServiceXS (Leiden, the Netherlands).

Proteomic analysis of soluble liver proteins

Cytosolic proteins were isolated and separated as described previously [13]. Briefly, a second portion of the foetal liver used for mRNA preparation was homogenised and centrifuged at $100,000 \times g$. Proteins in the supernatant were separated in the first dimension on BioRad immobilized $\mathrm{pH}$ gradient (IPG) strips ( $\mathrm{p} I$ 3-10) and in the second dimension on an $18 \times 18 \mathrm{~cm}$ linear SDS polyacrylamide gradient at $200 \mathrm{~V}$ for $9.5 \mathrm{~h}$. Gels were stained with colloidal coomassie brilliant blue, dried and scanned. Spots of interest were excised, digested with trypsin and the identities were determined by MALDI-TOF or LC/MS/MS mass spectrometry.

Statistical analysis

The data generated by the microarrays were analysed using the MadMax suite of programmes (https://madmax. bioinformatics.nl). All of the data met the appropriate quality control criteria and were normalised using the GCRMA (slow) programme. Relative changes in mRNA levels were determined using Linear Models for Microarray Data (LIMMA) module of GenePattern [16]. Analysis of the pathways involved was carried out using the GSEA programme [17].

The images of the two-dimensional SDS-PAGE gels of soluble proteins were analysed using PDQuest software (v7 BioRad, Hemel Hempstead, UK). Normalised spot densities were analysed by two-way ANOVA for the effects of protein, oil and interactions (Genstat7). Peptide mass list profiles were analysed using the Matrix Science 'Mascot' web tool (http://www.matrixscience.com). A mascot score of at least 50 with $20 \%$ matched peptides $(p<0.05)$ covering at least $10 \%$ of the protein sequence was required for a positive identification.

\section{Results}

Maternal live weight gain was reduced in animals fed the low protein diet and the effect was greater in corn compared to soya oil diets (Table 1). In contrast, foetal growth was more sensitive to protein restriction and was unaffected by the oil type. The protein and oil in the diet did not affect litter size. Combining the data from the corn and soya oil groups showed that feeding the dam with an LP diet reduced the weight of the foetal liver by approximately $8 \%$, similar to the change reported previously [15]. Therefore, data from both corn- and soya oil-based diets were combined and analysed with respect to the protein content (HP or LP) of the maternal diet.

\section{Transcriptome}

Following normalisation, a total of 11,426 mRNAs were above the background level and expressed in foetal liver. Of these, 154 were upregulated and 15 downregulated in the LP group when compared to the HP group. The top 12

Table 1 Maternal and foetal characteristics at day 21 of gestation

\begin{tabular}{|c|c|c|c|c|c|c|c|c|c|c|c|}
\hline & \multicolumn{8}{|c|}{ Diet $(n)$} & \multicolumn{3}{|c|}{$p$ value (two-way ANOVA) } \\
\hline & \multicolumn{2}{|c|}{$18 \mathrm{C}(9)$} & \multicolumn{2}{|l|}{$9 \mathrm{C}(6)$} & \multicolumn{2}{|c|}{$18 \mathrm{~S}(8)$} & \multicolumn{2}{|c|}{ 9S (10) } & \multirow[t]{2}{*}{ Protein } & \multirow[t]{2}{*}{ Oil } & \multirow[t]{2}{*}{ Protein $\times$ oil } \\
\hline & Mean & SEM & Mean & SEM & Mean & SEM & Mean & SEM & & & \\
\hline Dam live wt $(\mathrm{g})$ & 389 & 6 & 366 & 6 & 386 & 5 & 380 & 5 & 0.03 & $\mathrm{~ns}$ & 0.05 \\
\hline Litter size & 14 & 0.7 & 14.3 & 1.3 & 15.9 & 0.9 & 14.9 & 0.7 & $\mathrm{~ns}$ & ns & ns \\
\hline Foetal wt $(\mathrm{g})^{*}$ & 4.14 & 0.07 & 4.06 & 0.08 & 4.18 & 0.0 .6 & 4.00 & 0.06 & 0.012 & ns & ns \\
\hline Foetal liver wt $(\mathrm{mg})^{*}$ & 252.0 & 7.7 & 248.6 & 10.1 & 247.5 & 6.6 & 235.4 & 6.1 & 0.011 & ns & ns \\
\hline
\end{tabular}

Data are mean \pm SEM

*Female fetuses only and two-way ANOVA corrected for litter size as covariate (where $p<0.001$ ), ns: $p>0.05$ 
Table 2 GSEA analysis of pathways up or downregulated by protein deficient diet in the foetal liver

\begin{tabular}{|c|c|c|c|c|c|c|c|}
\hline Name & Size & ES & NES & $\begin{array}{l}\text { NOM } \\
p \\
\text { value }\end{array}$ & $\begin{array}{l}\text { FDR } \\
q \\
\text { value }\end{array}$ & $\begin{array}{l}\text { FWER } \\
p \text { value }\end{array}$ & Function \\
\hline \multicolumn{8}{|l|}{ Upregulated in HP compared to LP } \\
\hline YAO_P4_KO_VS_WT_UP & 52 & 0.573 & 2.015 & 0 & 0.015 & 0.013 & $\begin{array}{l}\text { Upregulated following progesterone } \\
\text { stimulation }\end{array}$ \\
\hline STEMCELL_COMMON_DN & 39 & 0.546 & 1.816 & 0 & 0.140 & 0.222 & $\begin{array}{l}\text { Depleted in stem cells compared to } \\
\text { differentiated }\end{array}$ \\
\hline IDX_TSA_UP_CLUSTER1 & 20 & 0.619 & 1.802 & 0.001 & 0.115 & 0.262 & $\begin{array}{l}\text { Downregulated following } \\
\text { differentiation of 3T3-L1 } \\
\text { preadipocytes }\end{array}$ \\
\hline HIPPOCAMPUS_DEVELOPMENT_POSTNATAL & 43 & 0.524 & 1.782 & 0.001 & 0.117 & 0.343 & \\
\hline IGF1_NIH3T3_UP & 31 & 0.553 & 1.759 & 0.001 & 0.128 & 0.441 & $\begin{array}{l}\text { Upregulated by treatment of NIH3T3 } \\
\text { cells with IGF-1 }\end{array}$ \\
\hline ST_ERK1_ERK2_MAPK_PATHWAY & 26 & 0.570 & 1.747 & 0.004 & 0.123 & 0.48 & $\begin{array}{l}\text { The Erk1 and Erk2 MAP kinase } \\
\text { pathways regulated by Raf, Mos, } \\
\text { and Tpl-2 }\end{array}$ \\
\hline PGC1APATHWAY & 20 & 0.600 & 1.735 & 0.001 & 0.127 & 0.542 & PCG-1a is a coactivator for receptors \\
\hline BIOPEPTIDESPATHWAY & 36 & 0.521 & 1.703 & 0.009 & 0.163 & 0.683 & \\
\hline ELONGINA_KO_UP & 104 & 0.434 & 1.689 & 0.001 & 0.170 & 0.742 & \\
\hline VEGFPATHWAY & 24 & 0.557 & 1.671 & 0.004 & 0.191 & 0.808 & $\begin{array}{l}\text { Vascular endothelial growth factor } \\
\text { (VEGF) promotes blood vessel } \\
\text { formation }\end{array}$ \\
\hline POD1_KO_DN & 352 & 0.393 & 1.670 & 0.000 & 0.174 & 0.808 & \\
\hline ECMPATHWAY & 20 & 0.575 & 1.662 & 0.009 & 0.176 & 0.835 & $\begin{array}{l}\text { Extracellular matrix induces integrin- } \\
\text { mediated FAK phosphorylation }\end{array}$ \\
\hline \multicolumn{8}{|l|}{ Downregulated in HP compared to LP } \\
\hline DCPATHWAY & 17 & -0.535 & -1.783 & 0.008 & 0.186 & 0.358 & Secretion of cytokines \\
\hline CYTOKINEPATHWAY & 18 & -0.441 & -1.543 & 0.033 & 0.482 & 0.916 & $\begin{array}{l}\text { Differential chemokine receptor } \\
\text { expression }\end{array}$ \\
\hline
\end{tabular}

All genes on the chip were ranked by difference in expression between high and low protein diets using the $t$ test. An enrichment score (ES) was assigned to each gene, and the maximum ES (MES) was calculated for each gene set

NES enrichment score normalised for differences in gene set size; FDR $q$ value False Discovery Rate; FWER $p$ value Family Wise Error Rate

gene sets identified by gene set enrichment analysis (GSEA) as significantly enriched (nominal $p<0.005$ ) are shown in Table 2. There were two pathways that were downregulated (nominal $p<0.005$ ).

Proteome

Approximately, 900 discrete spots were identified on the two-dimensional SDS-PAGE gels of soluble proteins from the foetal liver. Analysis of the spot densities by two-way ANOVA identified 31 spots $(p<0.05), 15$ upregulated and 17 downregulated in LP compared to HP. The identities of the proteins more abundant in the HP compared to the LP group, the fold changes and their possible functions are shown in Table 3. The proteins more abundant in the LP group compared to the HP group are shown in Table 4.

\section{Discussion}

Comparing the relative abundance of mRNAs and proteins gives an overall view of the processes taking place during hepatic development. Importantly, the two methods provide complementary information. GSEA of the microarray data gives a sensitive measurement of changes in the expression of related genes. It is important to bear in mind that although the two-dimensional SDS-PAGE analysis of proteins in the soluble fraction is not as sensitive as the transcriptome analysis, it does provide additional information on processes that do not depend on gene transcription. A change in the relative abundance of a given soluble protein spot on the gel is not necessarily accompanied by a change in the total abundance of that protein or in the corresponding mRNA. For example, post-translational modification of proteins may produce isoforms with 
Table 3 Proteins more abundant in HP group compared to LP

\begin{tabular}{|c|c|c|c|c|}
\hline Unigene & Full ID name & $\begin{array}{l}p \text { value } \\
\text { (protein) }\end{array}$ & $\begin{array}{l}\text { Fold change 18/ } \\
9\end{array}$ & Function \\
\hline Rn.40255 & f1-ATPase alpha chain alpha chain (EC 3.6.1.34), chain A & 0.033 & 2.58 & Mitochondria \\
\hline Rn.6987 & $\begin{array}{l}\text { Ribonuclease UK114 (EC 3.1.-.-) (14.5 kDa translational inhibitor } \\
\text { protein) }\end{array}$ & 0.016 & 1.93 & Protein synthesis \\
\hline Rn.5819 & Aspartate transaminase (EC 2.6.1.1), cytosolic & 0.014 & 1.53 & $\begin{array}{l}\text { Amino acid } \\
\text { metabolism }\end{array}$ \\
\hline Mm.193212 & Hydroxypyruvate isomerase homolog, Mus musculus (mouse) & 0.010 & 1.50 & \\
\hline Rn.103179 & Myosin regulatory light chain 2-B & 0.032 & 1.42 & Cell locomotion \\
\hline Rn.40255 & ATP synthase subunit alpha, mitochondrial [precursor] & 0.031 & 1.40 & Mitochondria \\
\hline Rn.29777 & Thioredoxin & 0.045 & 1.29 & Redox \\
\hline Rn.2498 & Adenine phosphoribosyltransferase & 0.004 & 1.27 & Energy metabolism \\
\hline Rn.202945 & Haemoglobin beta-II chain & 0.044 & 1.24 & \\
\hline Rn.1785 & L-Lactate dehydrogenase B chain (EC 1.1.1.27) (LDH-B) & 0.025 & 1.24 & Energy metabolism \\
\hline Rn.3846 & Proteasome subunit beta type-7 precursor & 0.034 & 1.21 & Proteolysis \\
\hline Rn.4214 & Uroporphyrinogen decarboxylase & 0.040 & 1.21 & \\
\hline Rn.10308 & Apolipoprotein A-I precursor & 0.005 & 1.18 & Lipid metabolism \\
\hline Rn.108187 & Protein-tyrosine-phosphatase (EC 3.1.3.48) isoenzyme AcP1 & 0.006 & 1.17 & \\
\hline Rn.30105 & Hypothetical protein, Rattus norvegicus & 0.061 & 1.17 & Unknown \\
\hline
\end{tabular}

The mean pixel density $(n=6)$ in each group, analysed by two-way ANOVA, and the $p$ value for protein $(n=12)$ are shown. Fold change calculated from the mean pixel density

Table 4 Proteins more abundant in LP group compared to HP

\begin{tabular}{|c|c|c|c|c|}
\hline Unigene & Full ID name & $\begin{array}{l}p \text { value } \\
\text { (protein) }\end{array}$ & $\begin{array}{l}\text { Fold change } \\
18 / 9\end{array}$ & Function \\
\hline Rn.103326 & ARP3 actin-related protein 3 homolog & 0.009 & 0.40 & Cytoskeleton \\
\hline Rn.11389 & Carnitine $O$-palmitoyltransferase (EC 2.3.1.21) II precursor, mitochondrial & 0.011 & 0.42 & Lipid metabolism \\
\hline Rn.6036 & $\begin{array}{l}\text { Glutathione } S \text {-transferase Yb-3 (EC 2.5.1.18) (Chain 4) (GST Yb3) (GST } \\
\text { class-mu 3) }\end{array}$ & 0.006 & 0.50 & Anti-oxidant \\
\hline Rn.37838 & Tpi1 Triose phosphate isomerase & 0.021 & 0.53 & Glycolysis \\
\hline Rn.2391 & Ornithine carbamoyltransferase (EC 2.1.3.3) precursor & 0.036 & 0.53 & Amino acid metabolism \\
\hline Rn.20397 & Ba1-651.pyrroline-5-carboxylate dehydrogenase & 0.005 & 0.62 & $\begin{array}{l}\text { Proline (amino acid } \\
\text { metabolism) }\end{array}$ \\
\hline Rn.202945 & Haemoglobin beta-II chain & 0.009 & 0.63 & \\
\hline Rn.5819 & Aspartate transaminase (EC 2.6.1.1), cytosolic & 0.014 & 0.63 & Amino acid metabolism \\
\hline Rn.55106 & Glutamate dehydrogenase $[\mathrm{NAD}(\mathrm{P})]$ (EC 1.4.1.3) precursor & 0.031 & 0.68 & Amino acid metabolism \\
\hline Rn.41002 & Tyrosyl-tRNA synthetase, cytoplasmic (EC 6.1.1.1) & 0.002 & 0.75 & Amino acid metabolism \\
\hline Rn.129558 & $\begin{array}{l}\text { Glyceraldehyde-3-phosphate dehydrogenase (phosphorylating) (EC } \\
\text { 1.2.1.12) }\end{array}$ & 0.045 & 0.76 & Glycolysis \\
\hline Rn.202968 & Serum albumin precursor & 0.063 & 0.76 & \\
\hline Rn.121972 & 40S ribosomal protein SA (p40) (34/67 kDa laminin receptor) & 0.044 & 0.77 & Protein synthesis \\
\hline Bt.2981 & $\begin{array}{l}\text { Guanine nucleotide-binding protein subunit beta 2-like } 1 \text { (receptor of } \\
\text { activated protein kinase } \mathrm{C} \text { ) }\end{array}$ & 0.003 & 0.80 & $\begin{array}{l}\text { Protein amino acid } \\
\text { binding }\end{array}$ \\
\hline Rn.55106 & Glutamate dehydrogenase $[\mathrm{NAD}(\mathrm{P})](\mathrm{EC}$ 1.4.1.3) precursor & 0.006 & 0.81 & Amino acid metabolism \\
\hline Rn.203147 & Chaperonin containing TCP1, subunit 3 (Gamma) & 0.024 & 0.83 & Protein synthesis \\
\hline Rn.42859 & Nitrilase family, member 2 & 0.034 & 0.84 & \\
\hline Rn.55106 & Glutamate dehydrogenase [NAD(P)] (EC 1.4.1.3) & 0.005 & 0.86 & Amino acid metabolism \\
\hline
\end{tabular}

The mean pixel density $(n=6)$ in each group, analysed by two-way ANOVA, and the $p$ value for protein $(n=12)$ are shown. Fold change calculated from the mean pixel density 
different cellular functions. There is also a redistribution of some proteins between soluble cytosolic forms and insoluble membrane or organelle bound forms. This extra information gives insights into cellular functions carried out by mitochondria, intracellular membranes and the cytoskeleton.

There is a highly significant upregulation of genes related to progesterone signalling in the HP compared to the LP livers (FWER < 0.05). This indicates an important role for this hormone in response to an increase in maternal protein intake. Previous studies have shown that progesterone levels are reduced in the maternal circulation of dams fed low protein diets [4]. Other signalling molecules identified by GSEA are insulin-like growth factor (IGF) and vascular endothelial growth factor (VEGF), both of which are known from gene deletion studies to play essential roles in development [8, 9]. In addition, there is downregulation of cytokine signalling in the LP group. It is not clear whether these are all systemic changes or whether they also reflect local cell-cell interactions. Other pathways identified by GSEA suggest that the protein content of the maternal diet modifies cell differentiation in the foetal liver. Interactions between cells and the extracellular matrix are important elements of signalling between the different cell types that make up the developing liver. Network analysis using the GeneGo programme (http:// www.genego.com) suggested that a number of intracellular protein kinase cascades (JAK2, IRF9, ISGF3, NF-kB p65/p65, ActRIIA) are involved but unfortunately the present data do not allow us to establish which signalling pathways are active in which cells.

The changes in amino acid metabolism and mitochondrial function identified in the proteome of the foetal liver can be linked to the signalling pathways identified in the transcriptome by GSEA. For example, the peroxisome proliferator-activated receptor gamma coactivator-1alpha (PGC-1alpha) is a major candidate gene for diabetes-related metabolic phenotypes as it regulates multiple aspects of cellular energy metabolism, including mitochondrial biogenesis, hepatic gluconeogenesis, and the beta-oxidation of fatty acids through its interactions with a variety of transcription factors [19]. Progesterone signalling is also associated with metabolic changes, decreasing the rates of lipid synthesis in foetal hepatocytes [10]. Thus, changes in proteins involved in lipid metabolism in the foetus may be a consequence of altered progesterone.

With the present data set, it is still difficult to separate changes that are direct consequences of a change in the metabolite supply from those that are indirectly caused by other factors such as IGF signalling. The foetus and its placenta do not require positive growth factors from the mother, suggesting that the nutrient supply generates signals that regulate foetal growth [14]. Mammalian cells mount an active response to amino acid deficiency in vitro $[1,6]$; however, these well-characterised signalling pathways are not represented in the GSEA. This would be consistent with the observation that protein deficiency leads to the mobilisation of maternal proteins, maintaining amino acid concentrations in maternal and foetal sera leading to only minimal changes in the supply of amino acids delivered via the placenta [15]. These compensatory changes in metabolism are reflected in the differential abundance of a number of proteins associated with amino acid metabolism. However, the present data do not exclude a role for the amino acid sensitive pathways, especially in other foetal tissues where they may modify the production of systemic factors regulating organ growth. For example, the insulin-like growth factor binding proteins (IGFBPs) are believed to be involved in reducing the level of IGF-1 in the foetal plasma of rats fed low protein diets [3]. Inspection of the array data suggests that the mRNAs for both IGFBP-4 and IGFBP-6 tend to be elevated in the foetal liver (both $p=0.066$ ), whereas IGF-1 is unchanged $(p=0.3)$. The present results cannot rule out the possibility that IGF-1 and its binding proteins are produced by other foetal tissues under the control of elements which respond to the amino acid supply. These inter-organ interactions illustrate one of the deficiencies of this analysis and further studies are required to elucidate the interaction between nutrient supply and the expression of IGF and its binding proteins.

The changes in pathways associated with cell-cell signalling and motility suggest that tissue remodelling is also taking place. This appears to involve both Erk and MAP kinase signalling. Cell motility mediated by the extracellular matrix has a key role in developing the threedimensional structure of the liver. Because periportal hepatocytes around the afferent vessels have different metabolic capacities compared to the perivenous hepatocytes around the efferent vessels, a change in structure may alter function. Hepatocytes in the periportal zone are mainly involved in oxidative energy metabolism, gluconeogenesis, urea synthesis and bile formation, while glycolysis linked to liponeogenesis is carried out by hepatocytes in the perivenous zone [7]. The changes in the extracellular matrix are also affect vascularisation mediated through VEGF signalling, modifying blood flow through the adult organ. Together, all of these changes in the three-dimensional structure may have long-lasting effects on the essential metabolism of the liver.

Acknowledgments This work was supported by the Scottish Executive, Environment and Rural Affairs Department as part of the core funding to the Rowett Research Institute and by the European Union sixth Framework programme EARNEST (CT-2005-007036). Affymetrix arrays were obtained through the NuGO array pipeline (European Union sixth Framework programme FP6-506360). 


\section{References}

1. Avruch J, Long X, Ortiz-vega S, Rapley J, Papageorgiou A, Dai N (2009) Amino acid regulation of TOR complex 1. Am J Physiol Endocrinol Metab 296(4):E592-602

2. Desai M, Crowther NJ, Ozanne SE, Lucas A, Hales CN (1995) Adult glucose and lipid metabolism may be programmed during fetal life. Biochem Soc Trans 23:331-335

3. El Khattabi I, Gregoire F, Remacle C, Reusens B (2003) Isocaloric maternal low-protein diet alters IGF-I, IGFBPs, and hepatocyte proliferation in the fetal rat. Am J Physiol Endocrinol Metab 285:E991-E1000

4. Fernandez-Twinn DS, Ozanne SE, Ekizoglou S, Doherty C, James L, Gusterson B, Hales CN (2003) The maternal endocrine environment in the low-protein model of intra-uterine growth restriction. Br J Nutr 90:815-822

5. Gluckman PD, Hanson MA, Cooper C, Thornburg KL (2008) Effect of in utero and early-life conditions on adult health and disease. N Engl J Med 359:61-73

6. Jousse C, Averous J, Bruhat A, Carraro V, Mordier S, Fafournoux $\mathrm{P}$ (2004) Amino acids as regulators of gene expression: molecular mechanisms. Biochem Biophys Res Commun 313:447-452

7. Katz NR (1992) Metabolic heterogeneity of hepatocytes across the liver acinus. J Nutr 122:843-849

8. Krussel JS, Bielfeld P, Polan ML, Simon C (2003) Regulation of embryonic implantation. Eur J Obstet Gynecol Reprod Biol 110:S2-S9

9. Liu JP, Baker J, Perkins AS, Robertson EJ, Efstratiadis A (1993) Mice carrying null mutations of the genes encoding insulin-like growth factor I (Igf-1) and type 1 IGF receptor (Igf1r). Cell 75:59-72

10. Lorenzo M, Roncero C, Benito M (1986) The role of prolactin and progesterone in the regulation of lipogenesis in maternal and foetal rat liver in vivo and in isolated hepatocytes during the last day of gestation. Biochem J 239:135-139
11. Maloney CA, Lilley C, Cruickshank M, McKinnon C, Hay SM, Rees WD (2005) The expression of growth-arrest genes in the liver and kidney of the protein-restricted rat fetus. Br J Nutr 94:12-18

12. Maloney CA, Lilley C, Czopek A, Hay SM, Rees WD (2007) Interactions between protein and vegetable oils in the maternal diet determine the programming of the insulin axis in the rat. Br J Nutr 97:912-920

13. McNeil CJ, Hay SM, Rucklidge G, Reid M, Duncan G, Maloney CA, Rees WD (2008) Disruption of lipid metabolism in the liver of the pregnant rat fed folate deficient and methyl donor deficient diets. Br J Nutr 99(2):262-271

14. Owens JA (1991) Endocrine and substrate control of fetal growth: placental and maternal influences and insulin-like growth factors. Reprod Fertil Dev 3:501-517

15. Rees WD, Hay SM, Buchan V, Antipatis C, Palmer RM (1999) The effects of maternal protein restriction on the growth of the rat fetus and its amino acid supply. Br J Nutr 81:243-250

16. Reich M, Liefeld T, Gould J, Lerner J, Tamayo P, Mesirov JP (2006) GenePattern 2.0. Nat Genet 38:500-501

17. Subramanian A, Tamayo P, Mootha VK, Mukherjee S, Ebert BL, Gillette MA, Paulovich A, Pomeroy SL, Golub TR, Lander ES, Mesirov JP (2005) Gene set enrichment analysis: a knowledgebased approach for interpreting genome-wide expression profiles. Proc Natl Acad Sci USA 102:15545-15550

18. Widdowson EM, McCance RA (1963) The effect of finite periods of undernutrition at different ages on the composition and subsequent development of the rat. Proc R Soc Lond B Biol Sci 158:329-342

19. Yoon JC, Puigserver P, Chen G, Donovan J, Wu Z, Rhee J, Adelmant G, Stafford J, Kahn CR, Granner DK, Newgard CB, Spiegelman BM (2001) Control of hepatic gluconeogenesis through the transcriptional coactivator PGC-1. Nature 413:131138 